dwindling pagan tribes of the Malay Peninsula would disappear. The observations which Mr. Noone now records, however, suggest that in the group under notice recuperative forces are at work, which enable them at least to hold their own against the effects of Malayan contacts and the adoption by some of their number of the tenets of the Mahommedan faith. In the course of an economic and demographic survey in 1936, Mr. Noone found that in fourteen groups with a population estimated at 1,600 the number of children born to the average lowland Sernoi married. woman is $4 \cdot 15$, the model family also being four, but with a tendency to increase. The size of the family which ocrurs so many times as to contribute potentially more to a future generation than any other is five. With this figure as a characteristic, there is ground for hope for the future.

Fertility, reckoned on the basis of the number of children who grow to maturity and become effective in adding offspring to the group, is assessed on the average survival figure of $3 \cdot 003$, the largest number of deaths before maturity taking place under the age of six years. The sex ratio is 100 females to $107 \cdot 38$ males born; and this is practically unchanged at maturity at 100 and 107.54 respectively. These figures, taken in conjunction with other data recorded by Mr. Noone, point to the conclusion that while groups in which contacts have been recent appear to enter upon a stage during which the population suffers a disturbance of its reproduction rate, other groups have passed through this stage and have adjusted themselves well enough to be at least as viable as their more primitive and remoter hill cousins.

\section{Disease and Race}

A CASE which is of considerable interest in its bearing upon the racial incidence and distribution of disease is reported from Egypt by S. Azmy Pasha and A. F. Zanaty of Cairo (Lancet, 237, December 30, 1939). The patient in question, a man, thirty-five years of age, who had lived in Cairo for twelve years, but previously to that in the country, was admitted to hospital with anæmia in August 1938 and after discharge was re-admitted in a relapse in 1939. After a fortnight's treatment without improvement, a bone marrow puncture not only excluded an aleukæmic leucosis as well as a plastic anæmia, but also showed megaloblasts typical of Addisonian anæmia. Addisonian anæmia, the authors point out, has a distinct racial incidence. It is generally regarded as a disease of Nordic races and as less common among southern races. In America also a higher incidence has been recorded among immigrants from northern Europe (Anglo-Saxon) than among those of Latin extraction. It is also regarded as further supporting this view of racial susceptibility that the Finns, out of all races, are more liable to develop the disease when infested with Diphyllobothrium fatum-a parasite which produces a blood-picture indistinguishable from that of genuine Addisonian anæmia. The disease rarely occurs in Asiatics and is unknown in the tropies. In Egyptians it is extremely rare. The authors, after examining hundreds of anæmias, have found only this case now recorded, while another authority has encountered two cases only since 1935 .

\section{Demography of Madagascar}

IN his inaugural thesis (Thèse de Paris, No. 657; 1939) Dr. Félix Randriamanana states that a study of the population of Madagascar since the beginning of the century shows an annual rise, which was very pronounced during the first twelve years but underwent a decline during each of the subsequent twelve years. In 1936 the population was $3,777,951$ as compared with $2,244,876$ in 1900 . In 1904 and 1908 various devastating epidemies, especially smallpox, measles, malaria and influenza, had a considerable effect upon the population. The annual birth-rate has increased from 64,847 in 1906 to 88,351 in 1936 ; but the increase is probably more apparent than real owing to the notification of births being carried out more completely then previously.

During 1933-36 the death-rate was 20.7 per 1,000 , as compared with 28.5 in Réunion (1933-35), 24 in Egypt (1930-34), 22 in Cochin-China (1931-35) and $15 \cdot 7$ in France (1931-35). During the first year of life the mortality in 1934-36 was 177 per 1,000 births as compared with 83 in France $(1930-34)$ and 206 in Japan (1934). The maternal mortality in childbirth showed a rate of 100 per 1,000 births, this high rate being due to disease and the poor constitution of the mothers. The most prevalent epidemic diseases in Madagascar are plague and malaria at the beginning of summer (December), followed in April by influenza, measles, whooping cough and dysenteries. In June and July pulmonary diseases, especially pneumonia, predominate, followed by influenza, while in September and October more or less severe outbreaks of alimentary diseases are prevalent.

\section{Animal Organisers}

Current Science is to be congratulated on presenting to Indian readers a comprehensive résumé of research on organisers ("Organisers in Animal Levelopment", Supp. Curr. Sci., August 1939, Bangalore). There are eight articles contributed by the distinguished investigators, O. Mangold, E. Rotmann, J. Holtfreter, P. Weiss, W. Luther, C. H. Waddington, S. Hörstadius and C. M. Child. Four of the articles are in German, the remainder in English. There are numerous illustrations. The subjects discussed range from the general work of organisers during development and the special factors influencing their activities, to collateral fields of research such as the study of regeneration of lost parts and physiological gradients. A certain amount of repetition and overlapping is inevitable in a series such as this, and it would have been helpful if a summary of the articles could have been provided.

The story of the experimental work undertaken by Spemann and his collaborators at Freiburg im Breisgau on blastoporic organisation centres in the amphibian egg is well known in Great Britain. The old 'epigenesis' versus 'preformation' controversy 
was thereby revived in a new form. Yet where has it led us ? To a slightly better understanding of the laws governing development, but also to obstacles which defy further progress in the present state of our knowledge. For the moment, zoologists have exhausted the subject and await the arrival of a new idea. Some even deny the validity of the organiser theory, and it is possible that much of the work that has been done may be relegated historically to one of those attractive side avenues in science which forms a pleasant rendezvous for a while but is destined to be neglected later because it leads nowhere.

\section{Teaching of Statistics}

Is a paper read to the Royal Statistical Society on June 20, 1939, and printed, with the ensuing diseussion, in its Journal (102, 532 ; 1939), Dr. John Wishart pointed out, among other things necessary for the progress of the subject, the urgent need for a standard treatise on its mathematical side. There are many text-books on practical statistical methods, usually restricted to one particular field of application, such as economics, business statistics, psycho$\operatorname{logy}$, or biology and medicine, in which the reader has to accept the statements without proof. If a mathematical student asks where these proofs may be found, he may be told "You must look up the original papers, which you will not be able to understand". It is urgently necessary that a text-book should be produced to end this unsatisfactory state of affairs.

Dr. Wishart discussed in some detail what such a text-book should contain, and feared that it was beyond the powers of any one man to produce; he favoured a co-operative venture. However, many will differ from Dr. Wishart on this point, and prefer the incompleteness which may be found in the work of a single writer to the lack of unity characteristic of a book produced by a committee. In the interests of science it is desirable that we should not have to wait indefinitely until the ideal treatise can be produced. Let someone have the courage to make the attempt now ; there is no one better qualified for the task than Dr. Wishart himself.

\section{Meteorology in Southern Rhodesia}

THE meteorological report of the Department of Agriculture, Southern Rhodesia, for the year ended June 30, 1938, covers the period during which the Northern Rhodesia Weather Service was taken over from the British East Africa Meteorological Service by arrangement with the Governments concerned. After the transfer, the establishment of a new air route in Northern Rhodesia was announced by the Government of that country to replace the existing route via Broken Hill and Mpika, and this led to the setting up of a first-order meteorological station at Lusaka, while arrangements were made to open another at Kasama later. Civil aviation developed to twice its initial volume during the period in Southern Rhodesia, and the Service found it difficult to meet the increased demands for weather reports.
The formula used for the previous ten years for forecasting the seasonal rainfall gave a prediction of abundant rainfall for 1938-39, with a result that could not of course be indicated at the time of completion of this report. The only previous comparable prediction of abundant rainfall was for 1934-35, and was the most conspicuous of only three failures out of the previous nine predictions to forecast whether the rainfall would be above or below the average. On one of these three occasions the predicted and actual departures were so small that it can reasonably be regarded as a successful forecast, making the successes nearly eighty per cent, which is a very satisfactory result. It is stated that the predictions have proved of value, as may easily be credited in view of this high percentage. The report, as usual, includes extensive meteorological tables for a large number of stations for the year, among them those giving hourly values of several items for Salisbury Observatory.

\section{Mistletoe, Magic and Medicine}

THE October issue of the Bulletin of the History of Medicine contains an excellent survey by Dr. Leo Kanner, of Baltimore, of the history of mistletoe from the earliest times until the present day. The magic virtues formerly attributed to it were as follows: it was regarded as a promoter of grain and fruit harvests ; a fattener of live-stocks ; an incentive to milk production; a safeguard against ghosts and witches, nightmares and conflagrations ; a bringer of luck to farmers, home owners, hunters, warriors, wrestlers and travellers ; an agent which forces spirits to reveal their secrets; a discoverer of buried treasures, and a feeder of the mystic mandrake. It was also characteristic of its magic powers that mistletoe was regarded as a panacea, as it was used for the prevention and cure of plague, leprosy, fevers, syphilis, consumption, hæmorrhages, diseases of the heart and lungs, intestinal disorders, poór appetite, skin affections, nervous troubles and, most of all, epilepsy.

On the other hand, mistletoe was sometimes regarded as a baleful plant and was supposed to possess poisonous properties for which numerous remedies were prescribed by Galen and others. In the first half of the nineteenth century all the therapeutic properties of the mistletoe had become discredited, and it was not until 1906 that it became permanently established as a useful drug for the treatment of hypertension and later as a diuretic and styptic.

\section{Tests of a 4,000 kw. Gas-Turbine Set}

Prof. A. Stopora, in Engineering of January 5, gives a description and test results of a $4,000 \mathrm{kw}$. combustion-turbine generating set, recently constructed by Messrs. Brown, Boveri and Co., Ltd., of Baden, Switzerland, for the city of Neuchâtel. The set was built for installing in a bomb-proof chamber for use in emergencies, and consists of an axial-type air-compressor, a combustion chamber, a 